\title{
Imagination and Collaboration
}

Receiving the Corlis Benefideo Award for Imaginative Cartography was a tremendous honor not least because it came with an opportunity to address the NACIS community. As two independent mapmakers, we are grateful to have been spotted amidst this great sea of talent. What follows is an adaptation of our acceptance speech from the 2018 NACIS Annual Meeting in Norfolk, Virginia. Our original talk can be viewed here: youtu.be/3hrcziwEyPo.

\section{IMAGINATION}

OLIVER: Good Evening. In preparing our remarks, James and I sought to learn more about Corlis Benefideo. For those of you who don't know him, he's the mysterious cartographer at the heart of Barry Lopez's short story, "The Mappist," who heroically clings to his cartographic principles to the chagrin of his employers. Perhaps you can relate. Fictional as Benefideo may be, the values his character embodies are real: curiosity, dedication, imagination. So I must say how delighted we are that NACIS created an award to celebrate imagination. Serious imagination. In the serious world of adults, imagination is often relegated to the realm of children, as if we've outgrown its utility. We couldn't disagree more.

Imagination can be a way in. For the cartographer, an imaginative approach can clear a path into a particularly thorny dataset. For readers, it can open a door to understanding-suggesting what the map is about before they read a single word.

But what does it mean to be imaginative? If you agree with the Oxford English Dictionary that it means "having or showing creativity," then we must also define "creativity." For us, creativity is an exercise in surprise. It's about making unexpected connections. Unexpected conversions. This is like that. This becomes that.

For example, what if we took some data on life satisfaction, sense of purpose, happiness, and anxiety and converted each metric into a different facial attribute? Now what if we combined them and applied this conversion to all thirty-three of London's boroughs? Numbers becomes faces become a map.

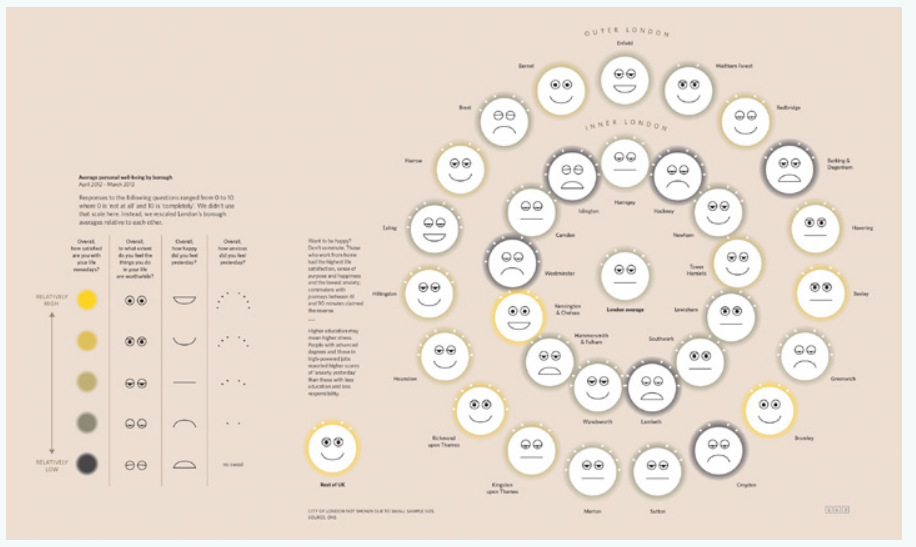

To be imaginative then, to make unexpected connections, you need to maintain a deep visual inventory of things to connect. We call this "keeping the well full." We go to art museums, travel, read, window shop, browse historical atlases and interior design catalogs, you name it. You never know when a visual reference will come in handy. So we're always looking, looking, looking. The idea for our map showing how to visit all 270 of London's Tube stations in a single day came while looking at a piece of art in Russell Square station not far from James's office. 
For another graphic, we had a list of haunted locations around London that we wanted to map. So I said, "OK brain, what's something visual and modular that involves ghosts?" This soon escalated to correspondence with the Pac-Man permissions teams at Namco in Japan. Upon submitting a draft, Namco informed us that "pretzel and pear cannot be used. Please [replace with] apple and strawberry." We replied with an amended design, to which we received the following: "Stems of apple and cherry have to be brown (please refer to the design guide for the exact color)." I took this as a good reminder that even when you're being imaginative, details matter. They're what make the metaphor convincing.

I did not always have the courage to make such imaginative leaps, at least not with cartography. I recall one of the first "map meetings" I attended as an entry-level designer at National Geographic. Senior designers, photo editors, text editors, researchers, and some of the top cartographers in the world were huddled around a map of Phoenicia. I noticed an opportunity to use color to link some labels and arrows, but I was just 23 years old, fresh out of school. Who was I to speak up?
I studied fine arts, not geography. For most of my life, maps were prompts for my imagination, not products of it. The earliest was a wooden puzzle of the fifty United States. Assembling those colored pieces over and over as a child induced a lasting synesthesia. To this day, when I imagine a state I see it as the color it was in that puzzle. California is lime; Michigan a sky blue; my home state of Pennsylvania, a chocolaty brown.

The memory of those shapes proved useful many years later during a pitch meeting at the magazine. The story team was marveling at a video in which Senator Al Franken drew a map of the US from memory. To me, this was not such a big deal. "I can do that," I said. I was not believed. A pen and a napkin were fetched, and I proceeded to replicate the wooden puzzle forever engraved in my mind. My colleagues found this demonstration remarkable enough to put it in the magazine. What was remarkable from my perspective was that they could not see what I saw.

Differences in how we see the world are what make the world interesting. They're also what make our work interesting. These differences arise from our range of life

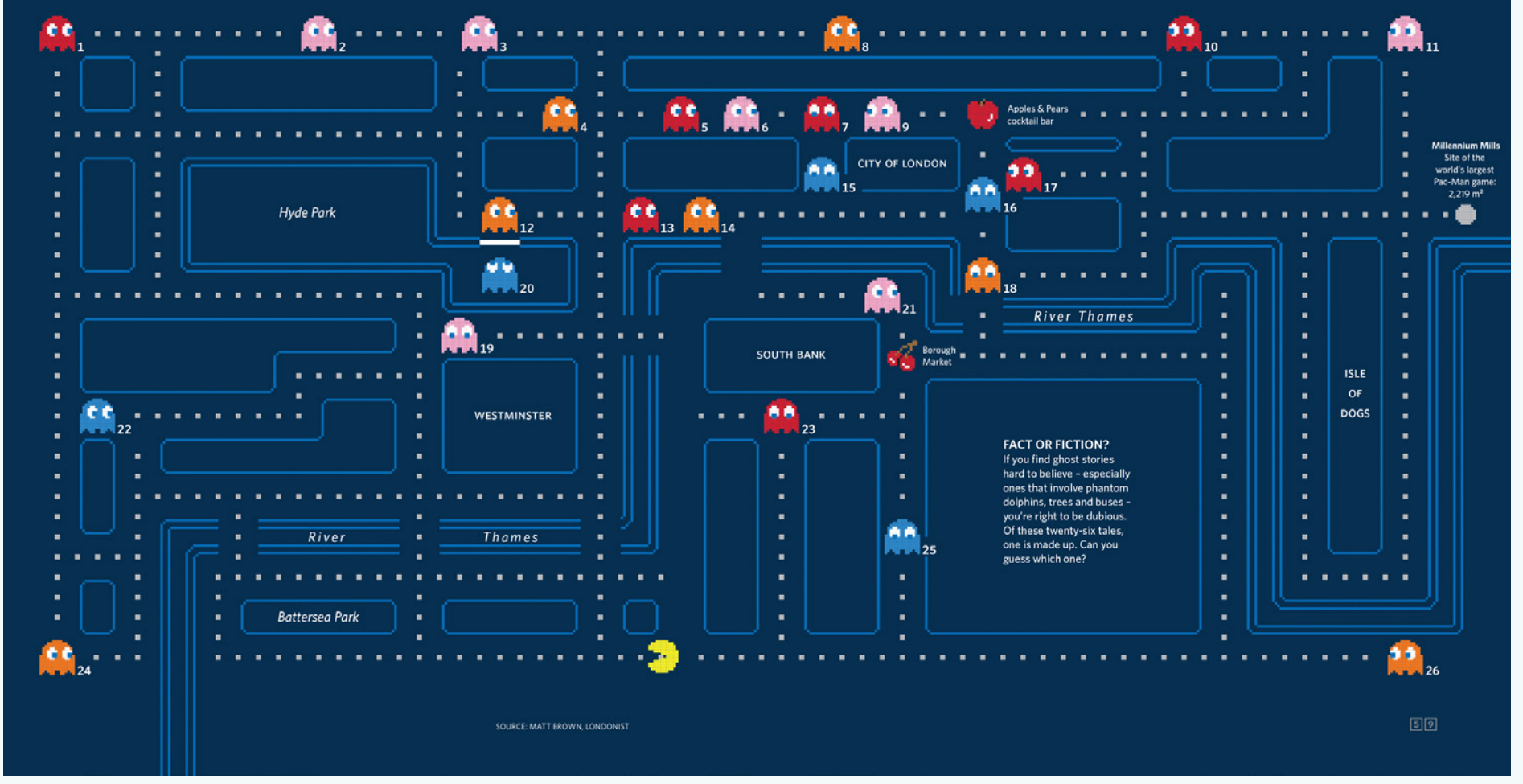


experiences-where we're from, where we've gone, what we've read, what we like, who we love, even those unfortunate events that happen to us. But in our professional lives - in companies, universities, and newsrooms-differences can be discouraged in favor of "the way we've always done things around here." We submit that it is precisely our imaginative differences that we must get into our work.

A few months after the napkin map, the magazine was preparing a special issue on the world's water crisis. A story was proposed on an EPA study that had found trace amounts of pharmaceuticals in fish in watersheds around the country. I was asked if I had an idea of how we might visualize it. "Easy," I said. "We'll make a fish out of pills."

I had begun to trust my imaginative instincts. And when those instincts told me to leave the magazine, to rent a

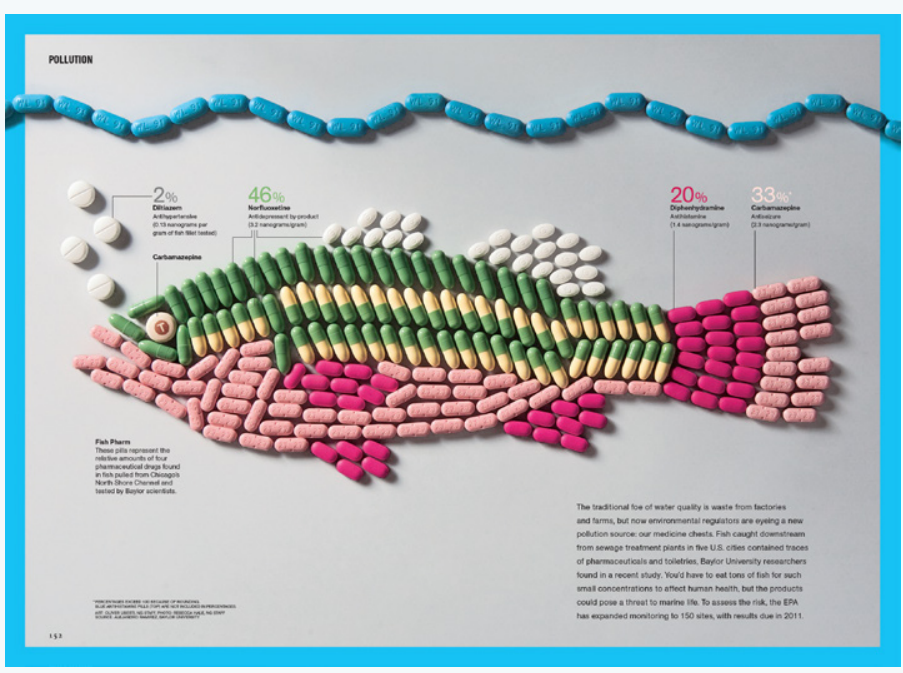

small house in Michigan, and to begin collaborating on a book of maps with a geographer named James, I listened.

\section{CURIOSITY}

JAMES: My ROUTE TO MAPPING came from collecting what I now know to be spatial data. As a teenager, I obsessed over mapping technology, specifically the Casio Pathfinder wristwatch. It had a compass in it. And a barometer. And an altimeter. It had enough memory to store twelve hours of temperature and altitude data. On family hiking holidays, I would provide near-continuous updates on the drop in temperature due to the environmental lapse rate as we walked uphill.

From moving weather fronts to human migration, I've always been curious to know how the world worked and how we could navigate through it. Geography offered answers. However, it wasn't until years later that I discovered my passion for mapping them. Even as an undergraduate I didn't set out to make maps. I was driven by collecting and analyzing spatial data. My first real passion for this came from glaciology, and mapping shrinking glaciers in Iceland and Alaska. I then hit a stumbling block. Glaciology quickly became physics - and I'm no good at physics. Still, the methods I had used in my fieldwork, such as geostatistics, gave me a framework for conceptualizing the world in data points. They'd also shown me how maps can bring mountains alive. So with an itch for mapmaking and still no real clue about physics, I was drawn towards GIS and population mapping. That choice ultimately led Oliver and I to cross paths.
His world of design and my world of mapping first united in 2010 when Oliver was still at National Geographic. I was studying for a $\mathrm{PhD}$ that focused on the geographic patterns of millions of surnames in Europe and beyond. Oliver sought help to produce a map of the most popular surnames in the US. When the map was nominated for an award in London in September 2012, Oliver flew over and stopped by my office to say hello. The success of the surnames map had got me thinking, what if we took all the data we could find-on happiness, house prices, art, violent crime, and life expectancy - and created a new visual guide to my home city for the twenty-first century?

London: The Information Capital captured a moment in the city's history. It was still on a high from the Olympics; the UK had just conducted the most detailed Census to date; more and more of its datasets were being released; and maps were more popular than ever thanks to the internet and a number of hugely successful exhibitions. We now realize that we were just starting to see the power of maps when combined with the promise of big and open data. Since the book was published in 2014, we have seen tremendous progress in this space to the point where cartography can sometimes seem like an arms race to map the world quicker and in more detail than ever before. 
To KeEP UP, it helps to have a collaborator. In many researcher-designer relationships, the designer comes in at the end. For us, the mapmaking process is an equal partnership from conception to the final map. When we find a promising topic or dataset, typically we'll start by discussing the editorial angle we want to take and possible projections or visual metaphors that could help us frame the story. I will produce initial exports. Oliver will then test crops and color palettes, and I will re-export the data accordingly. It's a constant back and forth.

For example, this graphic shows the origin-destination flows of commuters in Southern England. In R, I drew slightly transparent lines between where people live and where they work. I thought my export looked pretty good. Then in Illustrator, Oliver swapped my black background for blue and applied effects to make the lines glow.

A graphic that scales rectangles by the number of works each artist has in the Tate galleries started life as a basic treemap. Oliver then painstakingly broke the export into its constituent parts, transformed the rectangles into picture frames and sculptures, and arranged them salon-style in "the gallery." Turner is the artist with by far the most works in the Tate so we licensed one of his paintings to fill the biggest box. What could have been an uninspiring collection of boxes is instantly brought alive for the reader.
For our second book, Where the Animals Go, our collaboration expanded to include scientists all over the globe who were using new technology to track the movements of animals in unprecedented detail. This experience taught us that it's not fair to expect everyone who creates or analyzes spatial data to be cartographers. Many scientists create maps with an academic publication in mind and then move on without giving them a second glance. Others are nervous of sharing data with those outside their field for fear of their work being misrepresented or used without credit. We may disagree with these perspectives, but they persist. Oliver and I see one element of our work as being able to work with people with such concerns to bring their research to a broader audience.

Working together, geographer and designer, we help scientists find and show narratives in their data. Perhaps counterintuitively, this is mostly an exercise in data reduction. We are both fond of saying that a large part of our job is cleaning hairballs. Take "The Seals Who Map the Southern Ocean." This map started out as a mass of lines showing the routes traveled by hundreds of seals around Antarctica. The initial impact came from the sheer volume of tracks collected. Beyond that, we realized the tangle did not communicate much else. Our solution was to extract the journey of a single seal named Rudolf and add annotations and contextual detail such as bathymetry and ocean

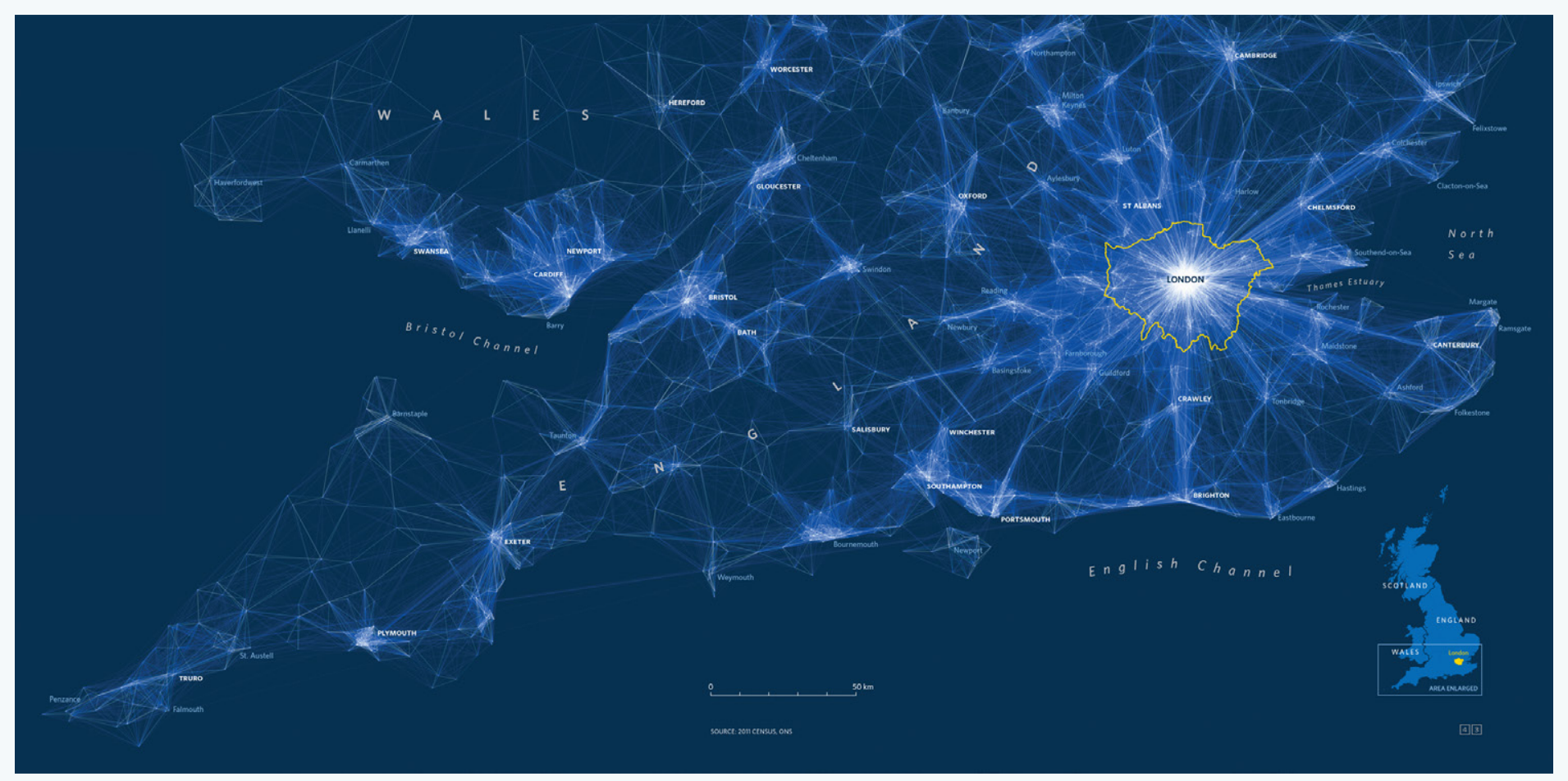


temperature to help readers grasp what a seal can teach us about warming seas.

This is the storytelling power of Small Data. Think of a nature documentary. You never hear about every gannet in the colony. The power comes from focusing on a breeding pair that represents the broader story. Barry Lopez's story would've been insufferable if instead of hearing about the life of Corlis Benefideo we had to read the biographies of every person in Fargo. We find story in specificity. But specificity takes more work. More reporting, more analysis, more time.

In "The Mappist," that sort of time-intensive mapping is what Benefideo longed for, what his employers loathed, and what drove him to strike out on his own to make 1,651 hand-colored maps of North Dakota. Oliver and I share a reverence for such historical methods. In fact, many "historical" maps can hold their own with the most data-driven of outputs of today.

Working together, geographer and designer, we're able to combine cartographic details and typographic hallmarks of the past with the computer power of today. Charles Booth's door-to-door "poverty map" of London remains among the most detailed social surveys ever undertaken. In The Information Capital, we used transparencies (as Benefideo might have done) to overlay Booth's 1889 map with current levels of deprivation.

Working together, geographer and designer, we're also able to imagine new roles for basemaps. Thanks to the range of Earth observation data now available, basemaps no longer have to be just backgrounds; they can become part of the story. For example, we can obtain meteorological data that reveals the winds encountered by albatrosses encircling Antarctica or satellite imagery that captures the ice floes used by snowy owls while hunting waterfowl. In fact, most of the data acquired for the Animals book was for the basemaps-over 200 gigabytes of terrain and vector layers, much of which did not make it to print. As we've learned, that's just part of the process.

With each map, with each book, you'd think the process would get easier. In some ways it has. What once took us a week, we can now complete in under an hour. Part of this is thanks to new software, part of this is thanks to experience, but most is due to the fluency we have developed working together.

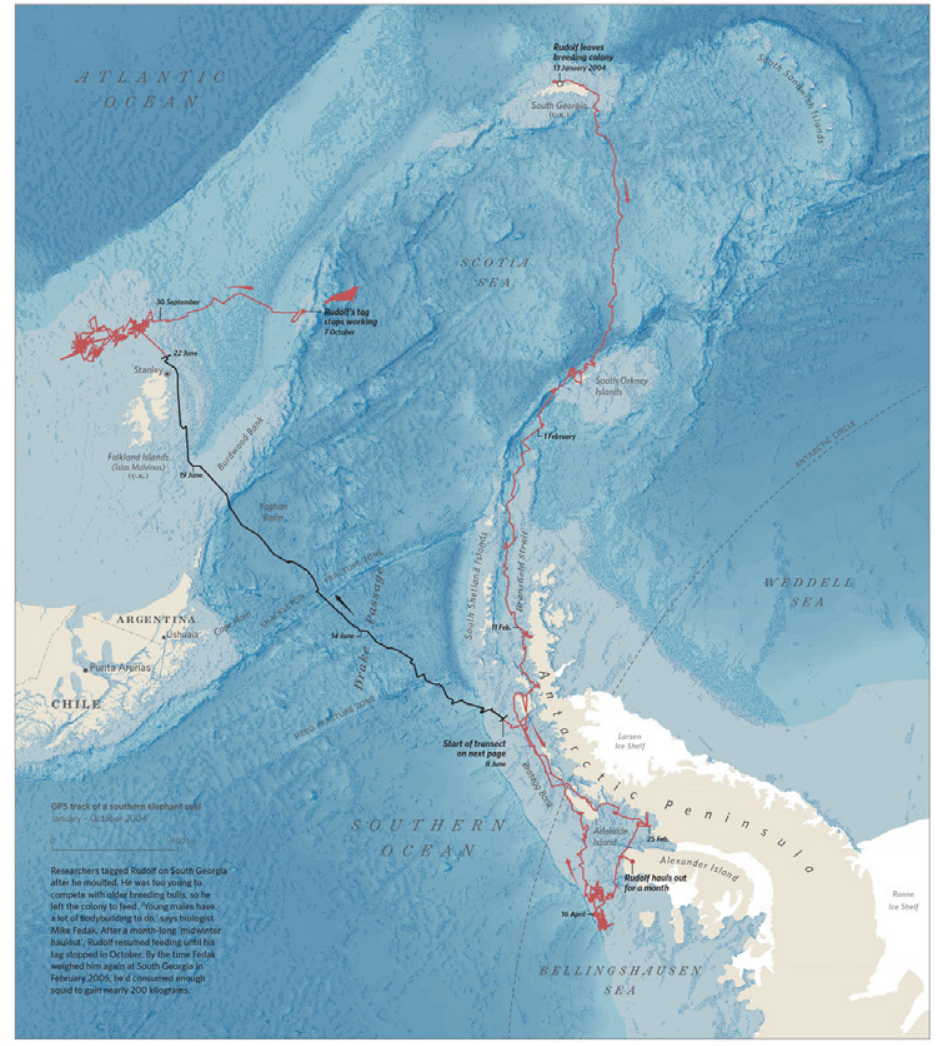

\section{The Seals Who Map the Southern 0cean}

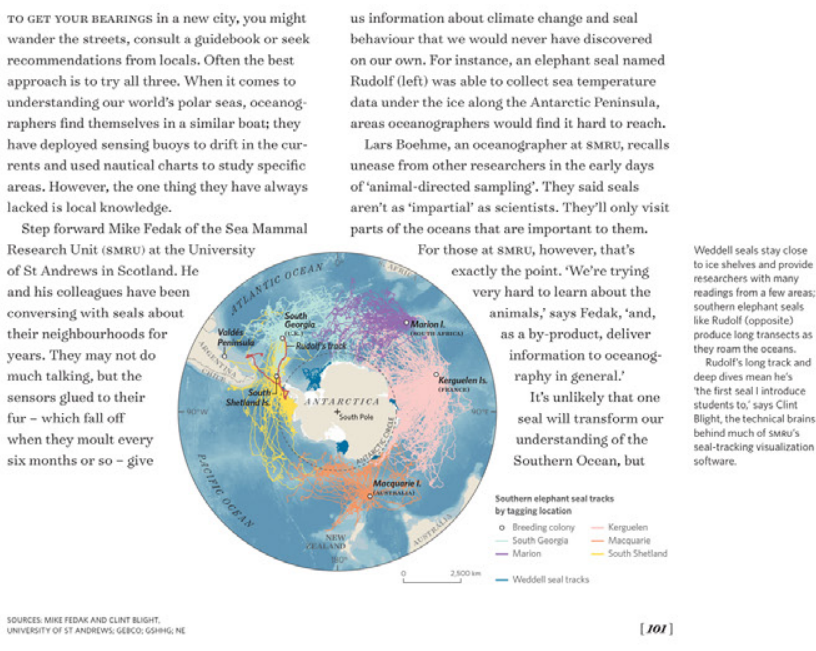


OliVER: Aspiring AUthors are often told to "write the book you want to read." For cartographers, the advice could be, "make the map you want to frame." As James and I were working on London: The Information Capital, we began to imagine a new type of book, one that we had always wanted but had never seen. Cartography books tended to fall into a few categories. There were instructional books that advised how to pick the appropriate projection or visualization technique. There were anthologies that gathered examples from the past or best practices from the present. There were gift books full of maps as jokes or oneoff concepts. And there were, of course, atlases.

What we hadn't seen were collections of original maps designed to comment on the world we live in now. "What if," we wondered. What if we took a step back and used maps to reflect upon larger patterns? To us, the distinction was like the difference between a news article and an essay. We need both. And in writing and photography, we get both. A previous recipient of this award, Rebecca Solnit, builds each of her essay collections as an ensemble. Top photojournalists build a point of view through photo essays not single shots. Where, we wondered, was an equivalent for cartography?

With London: The Information Capital and Where the Animals Go, we aimed to build a case through a series of "data essays." In London, it was a case for what data can reveal about life in a twenty-first century city. In Animals, what data can now tell us about the natural world. In both, we tried to take the long view. To put the present in the context of history while also looking to the future.

James and I are now at work on a new book. We've gathered data, designed spreads, written stories. But we're still going back and forth on the book's title because one of the nagging questions that we continue to revisit throughout our process is: what are we trying to say? What's our point of view? What is the sum of 100 maps?

Originally, our publisher commissioned our London book under the working title: London Infographics. In a way, that's a perfect example of how many editorial desks think of maps and graphics - as singular things about a subject: a map of London; a chart of population over time; or, as the narrator of "The Mappist" modestly described his own achievements, "some illustrations, however well done."
After James and I had produced a few dozen such "illustrations," we realized that the whole was communicating something more than its parts. We realized that this collection of data, pulled from public data stores and open data policies at the national and city level, would not be possible in any other city at that time. So the sum of 100 maps became not London Infographics but London: The Information Capital. The maps themselves were making an argument for open data, for London as an example for the rest of the world, for the power of maps-and mapmakers-to help inform policy and to improve our lives.

Flip through a magazine or scroll through a site and you'll often see the map as the accompaniment, a complementary figure that helps elucidate "the main story." It is our firm belief that maps can be the main story. We believe that you, the cartographer, can be the lead. You have a voice on par with writers and photographers. You have the power to make patterns visible. You have the power to show the change we see in this world. You have the power to warn, to reveal, to defend, to delight, to connect, to direct, to focus, to fascinate. You have the power to fire the imagination of a new generation, just like The City of Ascensions did for Phillip Trevino in "The Mappist," just like those wooden puzzles and Casio Pathfinders did for us decades ago.

At the end of "The Mappist," Corlis Benefideo says, "the real question, now, is what will you do?"

It's a good one. A few suggestions:

To power your imagination, trust your instincts and keep the well full. At conferences, go to sessions on subjects you know nothing about.

To take your maps to the next level, find a collaborator.

And to find your voice, take a cue from Mr. Benefideo himself. You don't have to retreat to North Dakota (or Michigan), but allow yourself time to push an idea as far as it'll go. If there's a subject you're passionate about, don't stop with a single map. Make a lot of maps. Maybe not 1,651 , but enough to hear what they're starting to say.

Because you, the mappists, have a voice. And we want to hear it. 